\title{
Numerical Simulation Study of Booming Effect in Fast Currents of Inland River
}

\author{
Rongchang Chen ${ }^{1, *}$, Chen Liu ${ }^{1}$, Xiaofeng Luo ${ }^{2}$ and Wei Shen ${ }^{1}$ \\ ${ }^{1}$ China Waterborne Transport Research Institute, Beijing, 100088, P.R. China \\ ${ }^{2}$ Nanjing Hydraulic Research Institute, Nanjing, 210029, P.R. China
}

\begin{abstract}
In the downstream tidal section of the Yangtze River, nine kinds of combinations of hydrological environmental conditions are considered, including the annual average runoff flow, the annual average peak flow and the flood control design flow, as well as the three conditions of spring, medium and neap tides. By means of the numerical simulation method, the effective performance parameter values for conventional intercepting boom under different environmental conditions are obtained by simulating 9 kinds of maximum current speed to withstand, Max.CS, respectively. The results show that, in the downstream fast current tidal section of the Yangtze River, for the boom performance index of Max.CS, the relatively extensive applicability value should be $3.0 \mathrm{kn}$ under the condition of the annual average runoff flow; $4.0 \mathrm{Kn}$ should be selected under the condition of the annual average peak flow; and $4.5 \mathrm{Kn}$ should be selected under the flood control design flow. This study can provide technical support for the design, selection and use of booms in downstream waters of the Yangtze River.
\end{abstract}

\section{Introduction}

A marine oil spill accident from ship would severely pollute water environment and water resources due to the polluting characteristic of ship fuel oil. Compared with the coastal waters, inland waters are relatively closed and most are used for drinking water sources, so inland waters are far heavily affected by oil spill accidents in the damages to ecological environment and negative social impacts. For example, the oil spill of thousands of tons from the explosion of the tanker Jiangyou 423 in Qixia, Nanjing, on 3 June 1997, caused heavy losses to the ecological environment of the waters [1].

Booms for oil spill are major measures for emergency response in inland waters. The functions of booms in emergency response can be mainly divided into booming interception and diversion. The boom deploying schemes can be divided into wrapping, dragging, inducing, intercepting, V-shaped deploying and other methods. The interception effects of the boom depend mainly on whether the performance parameters of the boom suite for the environmental conditions of the waters. At present, the type specifications and technical parameter designs of the conventional booms are mainly based on the coastal environmental conditions. The booms for the inland waters can usually select from the types of the coastal booms directly. So, there are not yet conventional booms fully applicable to tidal section of inland rivers that can work effectively in fast currents.

There are more than 25000 operating berths in inland waterway of China, including more than 400 berths of ten thousand tons and above. Daily average standard ship flow in the main channel of the Yangtze River is more than 600 ships in a year. With the increase of ship traffic volume and the development of large-scale ships, the risk of oil spill accidents trend to increase in the Yangtze River. Therefore, it is of great significance to study the oil spill emergency response in the Yangtze River and other inland waters, especially the booming effects.

\section{Analysis on performance indexes of booms}

The technical performances and basic quality requirements of the oil booms are specified in Oil Boom (JT/T 465-2001), a transport industry standard, which is suitable for the solid float, fencing, external tension, inflatable, shoal, fireproofing and other conventional types of oil booms. The waters in the environmental conditions of the waters used can be divided into four categories of calm water, calm water-significant current, protected water and open water according to the wave height and water current speed. See Table 1.

Table 1. Division of water types.

\begin{tabular}{|c|c|}
\hline Water & Wave height and current speed \\
\hline calm water & $\begin{array}{c}\text { Wave height } 0-0.3 \mathrm{~m} \text { or current } \\
\text { speed }<0.4 \mathrm{~m} / \mathrm{s}(0.78 \mathrm{Kn})\end{array}$ \\
\hline $\begin{array}{c}\text { calm water- } \\
\text { significant current }\end{array}$ & $\begin{array}{c}\text { Wave height } 0-0.3 \mathrm{~m} \text { and current } \\
\text { speed } \geqslant 0.4 \mathrm{~m} / \mathrm{s}(0.78 \mathrm{Kn})\end{array}$ \\
\hline
\end{tabular}

\footnotetext{
* Corresponding author: chenrongchang@wti.ac.cn
} 


\begin{tabular}{|c|c|}
\hline protected water & Wave height $0-1 \mathrm{~m}$ \\
\hline open water & $\begin{array}{c}\text { Wave height } 0-2 \mathrm{~m} \text { or wave } \\
\text { height }>2 \mathrm{~m}\end{array}$ \\
\hline
\end{tabular}

Commonly used booms include solid float, solid float PVC, fast deploying and other types, of which the solid float boom with wrapping material of rubber has relatively stronger current speed to withstand. The booms currently being provided for terminals handling dangerous cargo in the Yangtze River downstream are mainly composed of solid float rubber booms and solid float PVC booms. The total height of the solid float boom used in inland waters is generally $600-1100 \mathrm{~mm}$, and the boom with a total height of $1200 \mathrm{~mm}$ or above is mostly used in coastal and open sea areas with heavy stormy waves. For parameter series of maximum current speed to withstand (Max.CS), maximum wave height to withstand (Max.WH), maximum wind speed to withstand (Max.WS) and overall height $(\mathrm{OH})$ of the conventional rubber solid float boom, see Table 2. For the relationship between the maximum current speed to withstand and the overall height of the conventional solid float boom, see Figure 1.

Table 2. Main performance parameters of conventional rubber solid float boom

\begin{tabular}{|c|c|c|c|c|c|}
\hline $\begin{array}{c}\text { No } \\
\cdot\end{array}$ & Model & $\begin{array}{c}\text { Max.C } \\
\text { S (Kn) }\end{array}$ & $\begin{array}{c}\text { Max.W } \\
\text { H (m) }\end{array}$ & $\begin{array}{c}\text { Max.W } \\
\text { S (m/s) }\end{array}$ & $\begin{array}{c}\text { OH } \\
(\mathrm{mm}\end{array}$ \\
\hline 1 & WGJ600 & 1.5 & 1.5 & 10 & 600 \\
\hline 2 & WGJ800 & 2 & 2 & 15 & 800 \\
\hline 3 & $\begin{array}{c}\text { WGJ100 } \\
0\end{array}$ & 2.5 & 2 & 15 & 1000 \\
\hline 4 & $\begin{array}{c}\text { WGJ110 } \\
0\end{array}$ & 2.5 & 1.5 & 16 & 1100 \\
\hline 5 & $\begin{array}{c}\text { WGJ120 } \\
0\end{array}$ & 3 & 2.5 & 20 & 1200 \\
\hline 6 & $\begin{array}{c}\text { WGJ130 } \\
0\end{array}$ & 3 & 2 & 18 & 1300 \\
\hline 7 & $\begin{array}{c}\text { WGJ140 } \\
0\end{array}$ & 3 & 3 & 20 & 1400 \\
\hline 8 & $\begin{array}{c}\text { WGJ150 } \\
0\end{array}$ & 3 & 2.5 & 20 & 1500 \\
\hline 9 & $\begin{array}{c}\text { WGJ160 } \\
0\end{array}$ & $3-4$ & 3 & 20 & 1600 \\
\hline 10 & $\begin{array}{c}\text { WGJ180 } \\
0\end{array}$ & $3-4$ & 3.5 & 25 & 1800 \\
\hline 11 & $\begin{array}{c}\text { WGJ200 } \\
0\end{array}$ & $3-4$ & 3 & 22 & 2000 \\
\hline
\end{tabular}

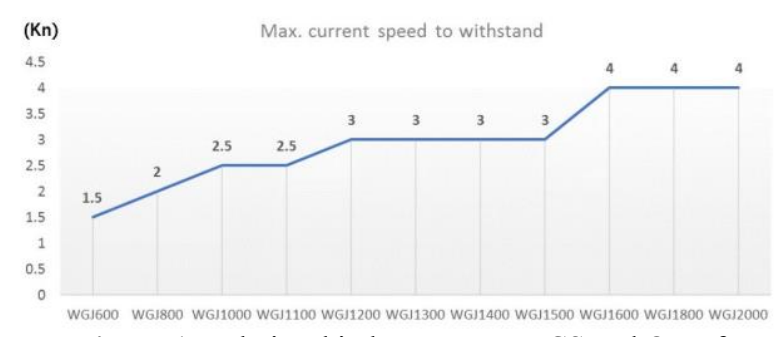

Figure 1. Relationship between Max.CS and $\mathrm{OH}$ of conventional boom

The current speed in inland river tidal section is affected not only by the changing runoff, but also by the tides. At the ebb tide, fast currents caused by the superposition effect would have a significant influence on the deploying and booming effect of the oil booms. Maximum effective current speed is between 1.5-6 kn, i.e. $0.77 \mathrm{~m} / \mathrm{s}-3.1 \mathrm{~m} / \mathrm{s}$, according to the evaluating results of various types of oil booming technologies by USCG [2]. No dividing the current speed above $0.4 \mathrm{~m} / \mathrm{s}(0.78 \mathrm{kn})$ in the industrial standard of Oil Boom will cause confusion to the type selecting of the booms in fast currents inland rivers affected by tides.

By numerical simulation method, the downstream sections of the Yangtze River affected by strong tides was selected to study the booming effect under various environmental conditions, which includes different combination of Max.CS and current states. The adopted values of Max.CS are $0.78 \mathrm{Kn}, 1.5 \mathrm{Kn}, 2.0 \mathrm{Kn}, 2.5 \mathrm{Kn}$, $3 \mathrm{Kn}, 3.5 \mathrm{Kn}, 4 \mathrm{Kn}, 4.5 \mathrm{Kn}$ and $5 \mathrm{Kn}$.

\section{Oil spill simulation scene analysis}

\subsection{Hydrodynamic simulation of the Yangtze River downstream}

The seasonal distribution of runoff in Datong of the Yangtze River was counted, and the frequency of open seas tidal range was analyzed. On this basis, a largescale two-dimensional mathematical model of tidal current from Datong to the Yangtze River Estuary was established. Simulation results of tidal currents in various scenes combining different runoffs and tidal range were calculated. In the simulation of booming effect, 9 kinds of currents scenes are made up, including the annual average runoff flow, the annual average peak flow and the flood control design flow [3], as well as the 3 conditions of spring, medium and neap tides in coastal observing station. See table 3 . The static wind condition was used for the simulation.

Table 3. Simulated flow scenes

\begin{tabular}{|c|c|c|}
\hline $\begin{array}{c}\text { Scene } \\
\text { name }\end{array}$ & Runoff in Datong $\left(\mathrm{m}^{3} / \mathrm{s}\right)$ & $\begin{array}{c}\text { Tide }(\mathrm{m}) \text { in coastal } \\
\text { observing station }\end{array}$ \\
\hline L1 & 28500 & 3.9 \\
\hline L2 & 28500 & 2.5 \\
\hline L3 & 28500 & 1.2 \\
\hline
\end{tabular}




\begin{tabular}{|c|c|c|}
\hline L4 & 57500 & 3.9 \\
\hline L5 & 57500 & 2.5 \\
\hline L6 & 57500 & 1.2 \\
\hline L7 & 85400 & 3.9 \\
\hline L8 & 85400 & 2.5 \\
\hline L9 & 85400 & 1.2 \\
\hline
\end{tabular}

\subsection{Scene analysis of oil spill accident}

\subsubsection{Oil spill accident location}

The downstream tidal section of the Yangtze River was selected as the simulated oil spill accident location. The high risk area of oil spill was determined by the ship Automatic Identification System (AIS for short). Composed of shore-based (base station) facilities and shipboard equipment, AIS is a digital navigation aid system and equipment which integrates network technology, modern communication technology, computer technology and electronic information display technology. Along with GPS, AIS can provide ship static data including ship name, call sign, MMSI, ship type, ship length and width, as well as ship dynamic data including ship's longitude \& latitude, heading, track and speed. The AIS activity status of the ships in the studying river section on one day in November 2017 is shown in Figure 2. It can be seen that the ships on Zhangjiagang north side waters (within the orange circle in the figure) are grouped into one route from two routes of the north and the south, and the intersection of waterways appears, which is a high risk area of ship traffic accidents and oil spill accidents. In the numerical simulation of this study, the central point of the high risk area is taken as the ship oil spill accident location to be simulated.

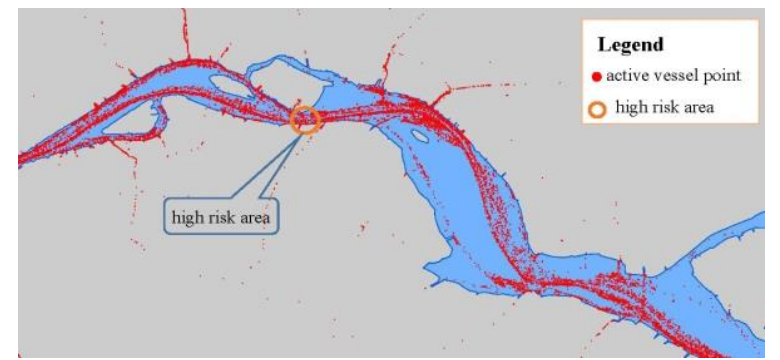

Figure 2. Ship AIS activities in the downstream section of the Yangtze River

\subsubsection{Oil spillage}

Extra serious and major oil spills on water are usually caused by transport ships carrying crude oil and its products. Leakage of ship fuel is oil spill accidents in ships with the highest frequency. This study assumes that a ship pollution accident occurs in the downstream water of the Yangtze River, and simulates the booming effect. A 10000 gross ton ship is generally equipped with 6 fuel tanks, with total fuel of 991.5 tons [4]. If a single tank leaks out, possible oil spillage in the accident is 165 tons.

\subsection{Numerical simulation method of oil spill trajectory and fates}

Oilmap is an oil spill trajectory and fates model developed by Applied Science Inc., USA. The trajectory model of Oilmap generalizes spilled oil into oil particles having mass and each oil particle represents a proper fraction of total oil spillage. Joint action of wind force, water current, wave and gravity current on floating oil is considered in the oil slick drift algorithm applied in the model, and the current-driving process is calculated with Lagrange particle tracking while the dissipation process is calculated with the Random Walk method. For the particle's drifting speed equation, see Equation (1) [5].

$$
U_{\text {oil }}=U_{\mathrm{w}}+U_{\mathrm{t}}+U_{\mathrm{r}}+\alpha U_{\mathrm{e}}+\beta U_{\mathrm{p}}
$$

Where, $U_{\mathrm{w}}$ is the speed component generated due to action of wind and wave, in $\mathrm{m} / \mathrm{s} ; U_{\mathrm{t}}$ is the speed component due to the action of water current, in $\mathrm{m} / \mathrm{s} ; U_{\mathrm{r}}$ is the speed component due to residual currents (e.g. gravity current), in $\mathrm{m} / \mathrm{s} ; U_{\mathrm{e}}$ is the speed component due to action of Ekman flow, in $\mathrm{m} / \mathrm{s} ; U_{\mathrm{p}}$ is the speed component due to action of squirt flow, in $\mathrm{m} / \mathrm{s} ; \alpha$ is 0 for floating particles and 1 for underwater particles; $\beta$ is 0 for non-squirt spill and 1 for squirt spill.

The fates model of Oilmap is used to calculate the results of oil spill weathering process which includes extension, evaporation, water carrying, emulsion and shoreline adsorption. Following the Law of Mass Conservation, the calculation process covers oil spills on water surface, in water bodies and substrates, in atmosphere, those absorbed on shorelines, and those manually contained and removed.

\section{Numerical simulation result analysis}

\subsection{Simulation results without booming interception measures}

The trajectory of pollutants after the oil spill accident under the conditions of L1 scene and static wind was simulated. Under the action of tide and runoff, the pollutants drift downstream rapidly at ebb tide; and the pollutants drift upstream at rising tide. In general, pollutants drift towards downstream under the action of the upstream runoff and tides and contaminate the northern shorelines.

48 hours after the accident, $1 \%$ of the leaked pollutants will volatilize into the atmospheric, $49.6 \%$ will float on the water surface and continue to move downstream, and $49.4 \%$ will be adsorbed on the shoreline and cause pollution. Pollutant drift trajectories 3 hours and 24 hours after the accident are shown in 
Figures 3 and 4 . The oil spill fate curve 48 hours after the accident is shown in Figure 5.

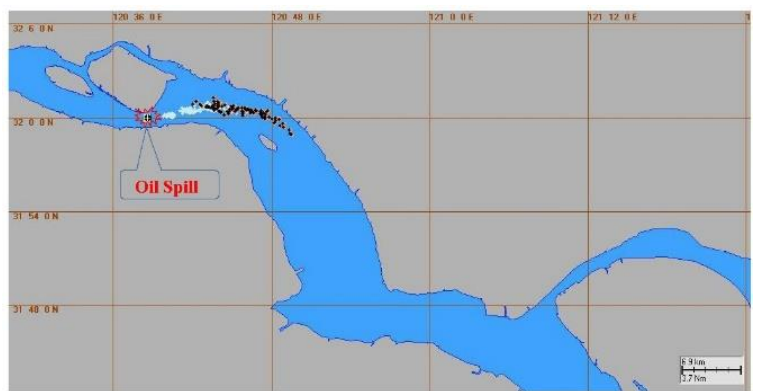

Figure 3. Pollutant drift trajectory 3 hours after oil spill accident.

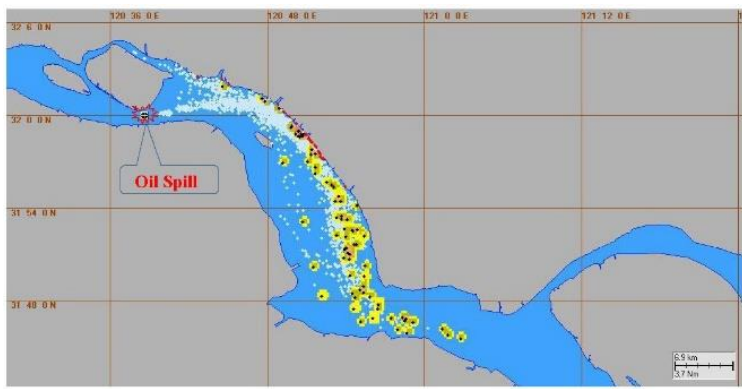

Figure 4. Pollutant drift trajectory 24 hours after oil spill accident.

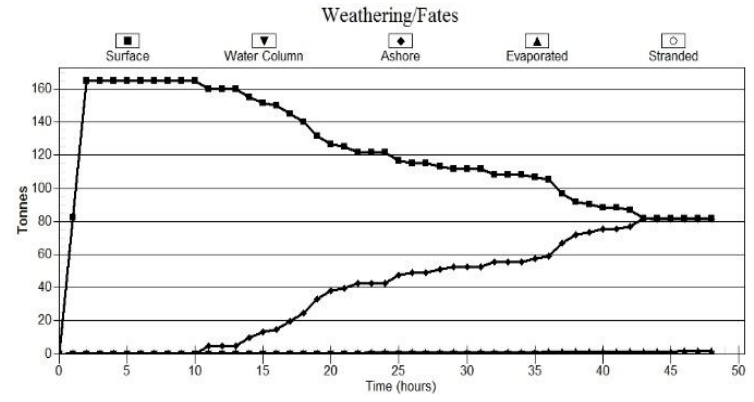

Figure 5. Oil spill fate curve 48 hours after oil spill accident.

\subsection{Simulation results of booming effects of different Max.CS}

The trajectory of pollutants after the oil spill accident under the conditions of L1 scene and static wind was simulated. According to the trajectory in Figure 3, deploying booms 3 hours after the accident was simulated. Because the influences of Max.CS on the booming effect are mainly investigated, the fullinterception boom deploying scheme with both sides of a boom fixed on the shore was adopted in order to eliminate interference of other parameters.

The simulation results show when Max.CS of the boom is $3.0 \mathrm{Kn}$ under the $\mathrm{L} 1 \mathrm{scene}$, the booming failure appears 15 hours after the accident, as shown in Figure 6. When Max.CS is $3.5 \mathrm{Kn}$ or above, the booming is very effective, as shown in Figure 7.

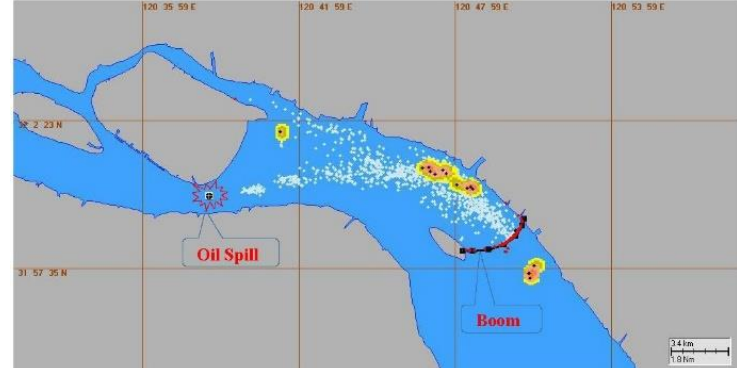

Figure 6. Booming effect of Max.CS 3.0Kn under L1 scene.

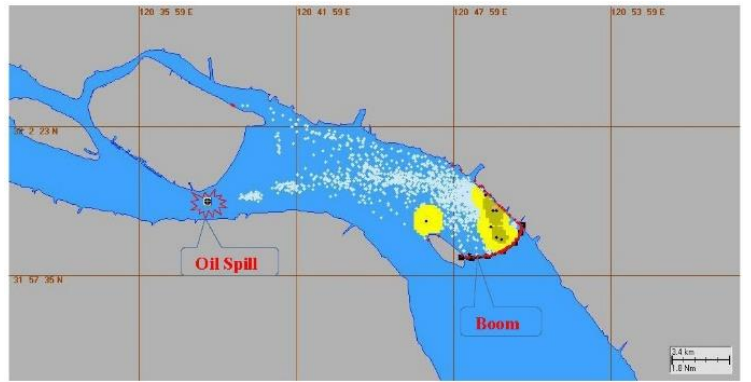

Figure 7. Booming effect of Max.CS 3.5Kn under L1 scene.

\subsection{Result analysis and recommendations}

In this study, the booming effects of 9 Max.CSs under 9 current scenes were simulated (see Table 4). The results are analyzed as follows:

(1) Under the conditions of annual average runoff flow, annual average peak flow and flood control design flow, the boom Max.CS should be no less than $2.5 \mathrm{Kn}$, up to $5.0 \mathrm{Kn}$. $3.0 \mathrm{kn}$ with relatively extensive applicability should be chosen under the condition of the annual average runoff flow; $4.0 \mathrm{Kn}$ should be chosen under the condition of the annual average peak flow; and $4.5 \mathrm{Kn}$ should be chosen under the flood control design flow.

(2) Normally, total height of the boom with $3.0 \mathrm{Kn}$ is $1200-1500 \mathrm{~mm}$, and total height of the boom with $4.0 \mathrm{Kn}$ is $1600-2000 \mathrm{~mm}$. In practice, the boom with total height more than $1200 \mathrm{~mm}$ is mostly used in coastal and open sea waters with heavy stormy waves. Total height of the boom designed for use in inland waters is generally less than $1200 \mathrm{~mm}$. At present, the conventional boom types are short of fast current resistant types with suitable total height.

(3) At present, there is no conventional boom meeting the requirement of Max.CS not less than $4.5 \mathrm{Kn}$. When an oil spill accident occurs under the condition of flood control design flow, most booms for oil spill interception will fail.

Table 4. Simulation results

\begin{tabular}{|c|c|c|c|c|c|c|c|c|c|}
\hline \multirow{2}{*}{$\begin{array}{c}\text { Scen } \\
\text { e }\end{array}$} & \multicolumn{10}{|c|}{ Max. CS (Kn) } \\
\cline { 2 - 10 } name & 0.7 & 1. & 2. & 2. & 3. & 3. & 4. & 4. & 5. \\
\hline L1 & $\times$ & 5 & $\times$ & $\times$ & $\times$ & $\sqrt{ }$ & $\sqrt{ }$ & $\sqrt{ }$ & $\sqrt{ }$ \\
\hline L2 & $\times$ & $\times$ & $\times$ & $\times$ & $\sqrt{ }$ & $\sqrt{ }$ & $\sqrt{ }$ & $\sqrt{ }$ & $\sqrt{ }$ \\
\hline L3 & $\times$ & $\times$ & $\times$ & $\sqrt{ }$ & $\sqrt{ }$ & $\sqrt{ }$ & $\sqrt{ }$ & $\sqrt{ }$ & $\sqrt{ }$ \\
\hline
\end{tabular}




\begin{tabular}{|c|c|c|c|c|c|c|c|c|c|}
\hline L4 & $x$ & $x$ & $x$ & $\times$ & $x$ & $\times$ & $\sqrt{ }$ & $\sqrt{ }$ & $\sqrt{ }$ \\
\hline L5 & $x$ & $x$ & $x$ & $x$ & $x$ & $\times$ & $\sqrt{ }$ & $\sqrt{ }$ & $\sqrt{ }$ \\
\hline L6 & $x$ & $x$ & $x$ & $\times$ & $\sqrt{ }$ & $\sqrt{ }$ & $\sqrt{ }$ & $\sqrt{ }$ & $\sqrt{ }$ \\
\hline L7 & $x$ & $x$ & $x$ & $\times$ & $x$ & $x$ & $\times$ & $x$ & $\sqrt{ }$ \\
\hline L8 & $x$ & $\times$ & $x$ & $\times$ & $x$ & $x$ & $\times$ & $\sqrt{ }$ & $\sqrt{ }$ \\
\hline L9 & $x$ & $x$ & $x$ & $x$ & $x$ & $\times$ & $x$ & $\sqrt{ }$ & $\sqrt{ }$ \\
\hline
\end{tabular}

According to the above simulation results, this study puts forward the following recommendations on the design selection and use of the oil booms: (1) For the design selection of the booms applicable to fast current section of inland rivers tidal affected, the key performance parameter considered should be the maximum current speed to withstand; (2) In the standard of Oil Boom, the range of the boom maximum current speed to withstand should be expanded, and the selectable range of the parameter value should be given according to different water environments, with maximum value no less than $5 \mathrm{Kn}$; (3) The development of both high current speed resistant and easy deploying with total height less than $1000 \mathrm{~mm}$ should be encouraged; (4) In the boom deploying, the capacity to resist fast current is increased by adjusting the angle, anchor position and balance weight of the deployed boom; (5) For different fast current sections of the inland river tidal affected, numerical simulation of the booming effect should be carried out before type selection to prevent the boom failure.

\section{Conclusions}

This study simulated 9 kinds of maximum current speed to withstand, Max. CS, of the conventional booms under 9 different combinations of runoffs and tidal states in the downstream waters of the Yangtze River by means of the numerical simulation method, and obtains the boom intercepting effectiveness under different environmental conditions.

The risks of oil spill accidents tend to increase with the growing traffic volume and ships in the downstream waters of the Yangtze River, so the studies on oil spill emergency responses are of importance. Due to fast current, complex waters, obvious effect by tides and other characteristics of the Yangtze River downstream waters, the correct selection of the oil boom, especially the performance parameter of maximum current speed to withstand, is playing a great role in enhancing the effects of the emergency responses. This study provides technical support for the design, selection and apply of the boom in the downstream waters of the Yangtze River.

\section{Acknowledgements}

This paper is based on the relevant achievements in Basic Scientific Research Projects of China Waterborne Transport Research Institute of Study on Integration
Technologies Associated with Emergency Response to Oil and Chemical Spill (WTI 61706), Study on Establishment of National Emergent Scientific Research Platform for Waterborne Oil Spill (WTI 61708), and Annual Report on the Development of Marine Oil Spill Emergency Response Technology (WTI 61627).

\section{References}

1. J Hui, Environmental protection in transportation, 21, 43-44 (2000)

2. U.S. Coast Guard Research \& Development Center, Oil Spill Response in Fast Currents - A Field Guide (Report No. CG-D01-02), Washington (2001)

3. J Ou, J R Ma, X N Zhang, X Y Zhang, Journal of Hohai University (Natural Sciences), 37, 258-262 (2009)

4. R C Chen, N Shi, K S Wang, Collection of Papers of the 1st International Global on Renewable Energy and Development Singapore 012172 (2017)

5. Applied Science Associates, Inc., Technical Manual Oilmap for Windows South Kingstown (2004) 